\title{
Zenbaki errealak eraikitzen
}

\author{
Javier Gutiérrez García eta Imanol Mozo Carollo* \\ Matematika Saila, Zientzia eta Teknologia Fakultatea, Bizkaiko Campusa. \\ Euskal Herriko Unibertsitatea (UPV/EHU) \\ *imanol.mozo@ehu.eus
}

DOI: $10.1387 /$ ekaia.14582

Laburpena: Zenbaki errealak funtsezko tresna eta oinarrizko eredu dira matematikaren arlo anitzetan. Hala ere, sarritan definizio zorrotzik emateari uko egiten zaio. Artikulu honek xede modura hartuko du historian zehar aurkeztu diren zenbait aukera azaldu eta hutsune hori betetzea. Bide honetan, zenbaki errealen definizio sintetikoa eta zenbaki arrazionalen deskribapen zorrotza egingo dugu, eta ondoren, Cantorren, Dedekinden eta Weierstrassen eraikuntza klasikoak aurkeztuko ditugu. Izan ere, matematikari horiek izan ziren eginbehar hau zuzen gauzatzen lehenengoak. Azkenik, Rota eta lankideen lana azalduko dugu, eta bide batez, erakutsiko dugu zenbaki errealen gorputza definitzerik badagoela beste ikuspuntu batetik, aljebraren ikuspegitik hain zuzen.

Hitz-gakoak: Zenbaki errealak, Cauchyren segida, Dedekinden ebakia.

Abstract: Even though real numbers are such an important tool and model in mathematics, no strict description is provided in many situations. The aim of this paper is to fill this gap by presenting some of these constructions. After giving a synthetic definition of the real numbers and a precise definition of rational numbers, we present the classical constructions of the real numbers proposed by Cantor, Dedekind and Weierstrass. Indeed, these were the first successful descriptions of the field of the real numbers. Finally, we explain the definition given by Rota and three other mathematicians, showing that this work can also be carried out by an algebraic approach.

Keywords: Real numbers, Cauchy sequence, Dedekind cut.

\section{ZENBAKI ERREALAK ERAIKI?}

Zenbaki errealak matematikaren arlo gehienetan agertzen zaizkigu. Batzuetan adibide nagusi gisa topatzen ditugu. Izan ere, arloan arloko nozio anitzen eredu izan ohi dira. Bestetan, oinarrizko definizio eta eraikuntzetan ezkuta daitezke. Gehienetan eskura ditugula onartu behar dugu, zenbait 
objektu eta erlazio berri definitzerakoan. Eta noski, zenbaki errealek matematikan duten nonahiko izaera hori dela eta, sarritan topatuko gara haiekin, matematika tresna nagusi duten arloetan.

Baina, zer ote dira zenbaki errealak? Askotan (esaterako analisi matematikoko testuliburu anitzetan) beraien oinarrizko propietateak azaldu eta aztertu bai, baina ez da definizio zorrotzik ematen. Hortaz, pentsa daiteke matematikaren oinarrien parte direla, nolabait, ideiez osaturiko mundu honen funtsezko adreiluetako bat. Baina hau benetako egoera al da? Ezin ditugu zenbaki errealak eraiki funtsezkoagoak diren egiturak erabiliz? Azkenengo galdera honi erantzuna ematen saiatuko gara eguneroko tresna hau eraikitzeko historian zehar eskaini izan diren zenbait aukera azalduz.

Artikuluak dibulgazio-izaera gal ez dezan, zehaztasun tekniko batzuk baztertu beharko ditugu, gehienak egia esan. Haatik, eraikuntza hauen ideia eta intuizio nagusiak azaltzea izango da gure helburua. Bertan topatuko dugu hein handi batean beraien garrantzia, hauetako eraikuntza gehienak nozio orokorragoen adibide nagusiak baitira. Ez da gure xedea zenbaki errealen garapenaren alderdi historikoak sakonki azaltzea ere, ez baikara matematikaren historian adituak.

Artikuluak honako egitura izango du: 2. atalean zenbaki errealen definizio axiomatikoa (sintetikoa) eskainiko dugu; definizioak balio lezake ondoren aurkeztuko ditugun eraikuntzak baliokideak direla frogatzeko. Horren ostean, 3. atalean, zenbaki osoak oinarritzat harturik zenbaki arrazionalak eraikiko ditugu, bide batez, aurrerago behin baino gehiagotan erabiliko dugun zatidura multzoaren nozioa adibide honekin gogoratuz. 4. atalean eraikuntza klasikoak landuko ditugu, Cantorren, Dedekinden eta Weiertrassen garaikideak diren lanak hiru azpiataletan, hurrenez hurren. Azkenik, Rota eta bere kideek garatutako proposamen aljebraikoa aztertuko dugu 5. atalean.

\section{DEFINIZIO SINTETIKOA}

Zenbaki errealak modu axiomatikoan defini ditzakegu. Horretarako gorputz ordenatu osoa egituraren nozioa behar dugu. Izan ere, zenbaki errealen modelo bat hurrengoan datza: $\mathcal{R}$ multzoa, 0 eta 1 multzo horretan bereiztutako bi elementu, + eta $\cdot$ bi eragiketa bitar eta $\leq$ erlazio bitarra non hau betetzen den:

(1) $(\mathcal{R},+, \cdot)$ gorputza da;

(2) $(\mathcal{R}, \leq)$ multzo guztiz ordenatua da, hots, $\leq$ erlazio erreflexibo, simetriko eta iragankorra da eta $\mathcal{R}$-ko edozein $x$ eta $y$ bi elementu elkarrekin konparagarriak dira, hau da, $x \leq y$ edo $y \leq x$; 
(3) gorputz-egitura eta ordena bateragarriak dira, hau da:

(i) $x \leq y$ bada, orduan $x+z \leq y+z$,

(ii) baldin $0 \leq x$ eta $0 \leq y$ orduan $0 \leq x \cdot y$;

(4) $(\mathcal{R}, \leq)$ Dedekind-osoa da, alegia, $A \subseteq \mathcal{R}$ bada eta goitik bornatuta badago orduan $A$-k gorena du.

Axioma hauek betetzen dituzten modelo guztiak isomorfoak dira. Beraz, definiziotzat har dezakegu. Baina, ba ote da axioma horiek betetzen dituen modelorik? Erantzuna baiezkoa da: bada gure definizioarekin bat datorren objektua eraikitzerik, baita modu desberdinetan egiterik ere.

Artikulu honen helburua horixe izango da hain zuzen ere. Zenbaki errealen eraikuntza desberdinak aurkeztuko ditugu. Froga daiteke bakoitzean definituko dugun modeloak gorputz ordenatu osoaren egitura duela. Hala ere, guk ez ditugu frogapen eta xehetasun guztiak eskaini. Beraz, baliokideak dira artikulu honetan aurkeztuko ditugun zenbaki errealen definizio guztiak.

\section{ZENBAKI ARRAZIONALAK DEFINITZEN}

Ohikoa da zenbaki arrazionalak zenbaki osoen zatikien bidez adieraztea:

$$
\frac{1}{2}, \frac{3}{4}, \frac{-5}{9}, \frac{1029}{-34322}, \ldots
$$

Horrela jokatuz, zenbaki arrazional bakoitzak ez dauka adierazpen bakar bat; izan ere, $1 / 2=2 / 4$ dugu. Orokorrean, $a, b, c$ eta $d$ zenbaki osoak izanik, $a / b=c / d$ izango dugu baldin eta soilik baldin $a \cdot d=b \cdot c$ bada. Adibidez:

$$
1 \cdot 4=4=2 \cdot 2 \text { denez } \quad \frac{1}{2}=\frac{2}{4} \quad \text { izango da } .
$$

Hau buruan izanik, saia gaitezen aurreko eraikuntza egokiago aurkezten (eta bide batez, honek aukera emango digu aurrerago beharko ditugun teknika batzuk azaltzeko). Defini dezagun $\mathbb{Z} \times(\mathbb{Z}-\{0\})$ multzoan erlazio hau:

$$
(a, b) \sim(c, d) \quad \text { baldin eta } a \cdot d=b \cdot c \quad \text { bada. }
$$


Noski, $(a, b)$ idaztean $a / b$ da buruan izango duguna, gure kasurako egokia izango den notazioa besterik ez baita. Erraz froga genezake definitu berri dugun erlazio hori baliokidetasun erlazioa dela:

- erreflexiboa da: $(a, b) \sim(a, b)$;

- simetrikoa da: $(a, b) \sim(c, d) \Rightarrow(c, d) \sim(a, b)$;

- eta iragankorra da: $(a, b) \sim(c, d)$ eta $(c, d) \sim(e, f) \Rightarrow(a, b) \sim(e, f)$.

Hortaz, baliokidetasun-klaseak defini ditzakegu, hau da, $(a, b) \in \mathbb{Z} \times$ $(\mathbb{Z}-\{0\})$ izanik, bere baliokidetasun-klasea multzo hau izango da:

$$
[(a, b)]=\{(c, d) \in \mathbb{Z} \times(\mathbb{Z}-\{0\}) \mid(c, d) \sim(a, b)\} .
$$

Baliokidetasun-klaseek $\mathbb{Z} \times(\mathbb{Z}-\{0\})$-ren partiketa osatuko dute. Begi bistakoa dugu, gainera,

$$
\frac{a}{b}=\frac{c}{d} \Leftrightarrow[(a, b)]=[(c, d)]
$$

betetzen dela. Hortaz, zenbaki arrazionalak adierazteko modu egoki bat aurkeztu dugu:

$$
\mathbb{Q}=\{[(a, b)] \mid a \in \mathbb{Z} \quad \text { eta } \quad b \in \mathbb{Z}-\{0\}\}=\mathbb{Z} \times(\mathbb{Z}-\{0\}) / \sim .
$$

Eragiketa aljebraikoak horrela definituko ditugu: $(a, b),(c, d) \in$ $\mathbb{Z} \times(\mathbb{Z}-\{0\})$ badira, orduan

$$
(a, b)+(c, d)=(a \cdot d+c \cdot b, b \cdot d) \quad \text { eta } \quad(a, b) \cdot(c, d)=(a \cdot c, b \cdot d)
$$

izango dira. Ordenari dagokionez, $(a, b) \leq(c, d)$ dela esango dugu baldin eta

$$
a \cdot d \leq c \cdot b
$$

bada. Eragiketa horiek ordena erlazioarekin eta baliokidetasun erlazioarekin bateragarriak dira, hau da, $(a, b),\left(a^{\prime}, b^{\prime}\right),(c, d),\left(c^{\prime}, d^{\prime}\right) \in \mathbb{Z} \times(\mathbb{Z}-\{0\})$ badira, non

$$
(a, b) \sim\left(a^{\prime}, b^{\prime}\right) \quad \text { eta } \quad(c, d) \sim\left(c^{\prime}, d^{\prime}\right)
$$

diren, orduan

$$
(a, b)+(c, d) \sim\left(a^{\prime}, b^{\prime}\right)+\left(c^{\prime}, d^{\prime}\right), \quad(a, b) \cdot(c, d) \sim\left(a^{\prime}, b^{\prime}\right) \cdot\left(c^{\prime}, d^{\prime}\right)
$$


eta

$$
(a, b) \leq(c, d) \Leftrightarrow\left(a^{\prime}, b^{\prime}\right) \leq\left(c^{\prime}, d^{\prime}\right)
$$

izango dugu. Hortaz, hau izango da definitu berri ditugun zenbaki arrazionalen eragiketak eta ordena erlazioa definitzeko modua:

$$
[(a, b)]+[(c, d)]=[(a \cdot d+c \cdot b, b \cdot d)], \quad[(a, b)] \cdot[(c, d)]=[(a \cdot c, b \cdot d)]
$$

eta

$$
[(a, b)] \leq[(c, d)] \Leftrightarrow(a, b) \leq(c, d) .
$$

Jakina, hemen aurkeztutako definizio formala bat dator egunero darabilgun zenbaki arrazionalen gorputzarekin. Hortaz, behin eraikuntza nola gauzatu daitekeen ikusita, ohikoa den modu informalean lan egingo dugu hemendik aurrera, atal bakoitzeko mamiaren azalpena erraztearren.

Kasu honetan erabili dugun prozedura edozein multzotan definitutako baliokidetasun erlazio batekin errepika genezake. Izan ere, ohikoa da objektu matematiko berriak definitzeko jadanik eskura ditugun objektuen baliokidetasun-klase bezala aurkeztea. Hori izango hain zuzen ere da zenbaki errealak eraikitzeko erabiliko dugun tekniketako bat.

Horrez gain, aljebran funtsezkoa den eraikuntza baten oinarrizko adibidea ere bada: zenbaki arrazionalek zenbaki osoen eraztunaren zatikien gorputza osatzen dute. Hau da, Q, zenbaki arrazionalen gorputza, Z parte duen gorputzik txikiena da. Nolabait, hau modu merkeena da zenbaki osoen biderketarekiko alderantzizkoak gehitzeko. Gainera, antzeko moduan jokatuz edozein integritate domeinu baten zatikien gorputza eraiki genezake.

\section{ERAIKUNTZA KLASIKOAK: CANTOR, DEDEKIND ETA WEIERSTRASS}

Sarreran esan dugun legez, zenbaki errealak matematikan edonon aurki ditzakegu, baina gaur egungo matematikan ez ezik, matematikaren historian zehar ere. Alegia, antzinako Grezian jadanik Pitagorasen eskolako kideek ezagutzen zituzten zenbaki irrazionalak; alabaina, XIX. mendera arte ez zen finkatu zenbaki errealen teoria zorrotzik. Horren zergatia XVIII. mendean kalkulu infinitesimalaren garapenean bila dezakegu, ordura arte erabilitako nozio lausoaren ahuleziak agerian utzi baitzituen. Cantor, Dedekind eta Weierstrass matematikariek ekin zioten zeregin horri. 


\subsection{Cantor: Cauchyren segidak}

1872. urtean Georg Cantor (1845-1918) matematikari errusiarrak aurkeztu zuen zenbaki errealak definitzeko modu hau [1], eta bera izan liteke eraikuntzarik ezagunena. Egia esan, Charles Méray (1835-1911) matematikari frantsesak ere bere aldetik garatu zituen ideia berberak hiru urte lehenago [5], baina garai hartan Frantziako matematikariek ez zuten interes handirik gai honetan. Beraz, matematikari gehienei Cantorren izena datorkie burura zenbaki errealen eraikuntza honetan pentsatzean.

Gogoratu bedi $a$ eta $a_{n}$ ( $n \in \mathbb{N}$ izanik) zenbaki arrazionalak badira, orduan $\left\{a_{n}\right\}_{n \in \mathbb{N}}$ segida $a$-rantz konbergentea dela $\left(\lim _{n \rightarrow \infty} a_{n}=a\right.$ idatziko dugu), baldin eta segidaren gaiak $a$-ren inguruan metatzen badira, hau da, edozein $\varepsilon$ zenbaki arrazional positibo baterako $n_{\varepsilon} \in \mathbb{N}$ existitzen bada non

$$
n \geq n_{\varepsilon} \Rightarrow\left|a_{n}-a\right| \leq \varepsilon .
$$

Kasu horretan argi dago beste baldintza hau ere betetzen dela: edozein $\varepsilon$ zenbaki arrazional positibo baterako $n_{\varepsilon} \in \mathbb{N}$ existitzen da non

$$
n, m \geq n_{\varepsilon} \Rightarrow\left|a_{n}-a_{m}\right| \leq \varepsilon .
$$

Aurreko baldintza betetzen denean $\left\{a_{n}\right\}_{n \in \mathbb{N}}$ segida Cauchyrena dela esango dugu ${ }^{1}$.

Lehen esan dugun bezala, segida konbergenteak Cauchyrenak dira, baina kontrakoa ez da egia. Adibidez,

$$
1, \frac{14}{10}, \frac{141}{100}, \frac{1414}{1000}, \frac{14142}{10000}, \ldots
$$

erreza da $\sqrt{2}$-ren garapen hamartarretik sorturiko zenbaki arrazionalez osaturiko segida Cauchyrena dela egiaztatzea (gaien arteko distantzia gero eta txikiagoa delako). Are gehiago, segidaren gaiak $\sqrt{2}$ zenbakiaren inguruan metatzen dira, eta beraz konbergentea izatekotan $\sqrt{2}$-rantz konbergentea izango zen, baina $\sqrt{2}$ ez da zenbaki arrazionala!

Adibide hau errepika genezake bai zenbaki arrazionalekin bai irrazionalekin. Beraz, zenbaki erreal bakoitzerako badago zenbaki hori limite mo-

1 Segida hauek analisi matematikoaren aintzindari izan zen Augustin-Louis Cauchy (1789-1857) matematikari frantsesaren izena hartzen dute. 
dura izango duen zenbaki arrazionalez osaturiko Cauchyren segida bat. Haatik, segida hori ez da bakarra izango, eta adibidez,

$$
2, \frac{15}{10}, \frac{142}{100}, \frac{1415}{1000}, \frac{14143}{10000}, \ldots
$$

zenbaki arrazionalez osaturiko Cauchyren segida ere $\sqrt{2}$-rantz konbergentea izango litzateke.

Zenbaki erreal bakoitza zenbaki hori limite modura duten zenbaki arrazionalez osaturiko Cauchyren segiden sortarekin identifika genezake. Baina, noiz dira Cauchyren bi segiden limiteak berdinak? Honek erantzun erraza dauka: $\left\{a_{n}\right\}_{n \in \mathbb{N}}$ eta $\left\{b_{n}\right\}_{n \in \mathbb{N}}$ zenbaki arrazionalez osaturiko Cauchyren bi segida badira, orduan limiteak berdinak dira baldin eta soilik baldin $\left\{a_{n}-b_{n}\right\}_{n \in \mathbb{N}}$ segida 0-rantz konbergentea bada.

Hortaz, hau izango da zenbaki errealak eraikitzeko modua:

Izan bedi $\mathcal{M}$ zenbaki arrazionalez osaturiko Cauchyren segiden multzoa. Multzo horretan baliokidetasun erlazio hau definituko dugu:

$$
\left\{a_{n}\right\} \sim\left\{b_{n}\right\} \Leftrightarrow \lim _{n \rightarrow \infty}\left(a_{n}-b_{n}\right)=0 .
$$

(Erraz frogatu daiteke erlazio hau baliokidetasun erlazioa dela.) Azpimarratu behar dugu hemen $\lim _{n \rightarrow \infty}\left(a_{n}-b_{n}\right)$ limiteak ez duela zertan existitu $\mathbb{Q}$-n. Noski $\mathbb{R}$-n existituko litzateke, baina zenbaki errealak eraikitzen ari gara orain, eta beraz ez litzateke egokia izango haiek erabiltzea. Haatik, erlazio honen definiziorako $\mathbb{Q}$-rekin nahikoa dugu, zeren limite hori 0 den kasua darabilgun. Laburbilduz, Cantorren zenbaki errealak honela definitzen dira:

$$
\mathbb{R}_{\text {Cantor }}:=\mathcal{M} / \sim .
$$

Beraz zenbaki errealak $\mathcal{M}$-ren segiden baliokidetasun-klaseak dira Cantorren eraikuntzan.

$\mathcal{M}$-ren segiden gaiz gaiko batuketa eta biderketa, hau da,

$$
\left\{a_{n}\right\}+\left\{b_{n}\right\}=\left\{a_{n}+b_{n}\right\} \quad \text { eta } \quad\left\{a_{n}\right\} \cdot\left\{b_{n}\right\}=\left\{a_{n} \cdot b_{n}\right\}
$$

Cantorren definizioko baliokidetasun erlazioarekin bateragarriak dira, hau da, $\left\{a_{n}\right\} \sim\left\{a^{\prime}\right\}$ eta $\left\{b_{n}\right\} \sim\left\{b^{\prime}\right\}$ badira,

$$
\left\{a_{n}\right\}+\left\{b_{n}\right\} \sim\left\{a_{n}^{\prime}\right\}+\left\{b_{n}^{\prime}\right\} \quad \text { eta } \quad\left\{a_{n}\right\} \cdot\left\{b_{n}\right\} \sim\left\{a_{n}^{\prime}\right\} \cdot\left\{b_{n}^{\prime}\right\} .
$$


Beste alde batetik, $\left\{a_{n}\right\} \leq\left\{b_{n}\right\}$ dela esango dugu, baldin eta $\left\{a_{n}\right\} \sim\left\{b_{n}\right\}$ edo $n_{0} \in \mathbb{N}$ existitzen bada non

$$
n \geq n_{0} \Rightarrow a_{n} \leq b_{n} .
$$

Kasu honetan ere, aurreko erlazioa eta baliokidetasun erlazioa bateragarriak dira, hau da:

$$
\left\{a_{n}\right\} \sim\left\{a_{n}^{\prime}\right\},\left\{b_{n}\right\} \sim\left\{b_{n}^{\prime}\right\} \text { eta }\left\{a_{n}\right\} \leq\left\{b_{n}\right\} \quad \text { badira, } \quad\left\{a_{n}^{\prime}\right\} \leq\left\{b_{n}^{\prime}\right\} .
$$

Hau izango da Cantorren zenbaki errealen eragiketa aljebraikoak eta ordena definitzeko modua: $\boldsymbol{a}=\left[\left\{a_{n}\right\}\right]$ eta $\boldsymbol{b}=\left[\left\{b_{n}\right\}\right]$ Cauchyren segiden baliokidetasun-klaseak badira, orduan

$$
\boldsymbol{a}+\boldsymbol{b}=\left[\left\{a_{n}+b_{n}\right\}\right], \quad \boldsymbol{a} \cdot \boldsymbol{b}=\left[\left\{a_{n} \cdot b_{n}\right\}\right] \quad \text { eta } \quad \boldsymbol{a} \leq \boldsymbol{b} \Leftrightarrow\left\{a_{n}\right\} \leq\left\{b_{n}\right\}
$$

izango dira.

Azkenik, $q$ zenbaki arrazionala $\boldsymbol{q}=[\{q\}]$ zenbaki errealarekin identifika dezakegu. Erraz ikusten da $\mathbb{R}_{\text {Cantor-ren eragiketa aljebraikoek eta orde- }}$ nak $\mathbb{Q}$-renak modu naturalean hedatzen dituztela eta $\left(\mathbb{R}_{\text {Cantor }}, \mathbf{0}, \mathbf{1},+, \cdot, \leq\right)$ gorputz ordenatu osoaren egitura duela.

Eraikuntza hau orokor daiteke; izan ere, bera da espazio metrikoen $o s a$ tzearen adibide nagusia. Gogoratu bedi espazio metriko bat osoa dela, baldin eta bertan definitutako Cauchyren segida guztiek limitea baldin badute. Osoa ez den espazio bat dugunean osoa izan dadin, behar ditugun limiteak (Cauchyren segida guztien limiteak, baina soilik horiek) gehitzeko modu kanonikoa hauxe dugu. Espazio horretan definitutako Cauchyren segiden multzoa hartuko dugu eta zenbaki arrazionalekin egin dugun antzera $\left\{a_{n}\right\}$ eta $\left\{b_{n}\right\}$ segidak berdintzat joko ditugu baldin eta

$$
\lim _{n \rightarrow \infty} d\left(a_{n}-b_{n}\right)=0
$$

bada, non $d$ espazio horren metrika den.

\subsection{Dedekinden ebakiak}

Ordenaren ikuspuntutik, zuzen errealak funtsezko propietate bat du: goitik bornatutako azpimultzo bakoitzak gorena du. Demagun $A$ goitik bornatutako zuzen errealaren azpimultzoa dela, hau da, $M$ zenbaki erreala existitzen dela, non $a \leq M$ den $a \in A$ guztietarako ( $M A$-ren goi bornea dela diogu); orduan $\alpha$ zenbaki erreala existitzen da eta zenbaki hori $A$-ren goi borne guztiak baino txikiagoa edo berdina da ( $\alpha A$-ren gorena dela diogu). Propietate hau Julius Wilhelm Richard Dedekind (1831-1916) matemati- 
kari alemaniarraren lanean agertu zen lehenengo aldiz eta hori dela eta, era honetako multzo ordenatuak Dedekind-osoak direla diogu.

Argi dago zenbaki arrazionalek ez dutela propietate hau. Adibidez, $A=\left\{p \in \mathbb{Q} \mid p^{2}<2\right\}$ multzoa goitik bornatuta dago $\mathbb{Q}$-n, baina ez dago beste goi borne guztiak baino txikiagoa den goi borne arrazionalik. Honetan datza Dedekinden lanaren gakoa: $\mathbb{R}$ da $\mathbb{Q}$ parte duen eta Dedekind-osoa den multzo ordenaturik txikiena. Eraikuntza hau Dedekinden ebaki delako kontzeptuan oinarrituta dago: $A \subseteq \mathbb{Q}$ ebakia dela diogu baldin eta lau propietate hauek betetzen baditu:

(D1) $A$ ez-hutsa da.

(D2) A goitik bornatuta dago, $(q \in \mathbb{Q}$ existitzen da, non $p \leq q$ den $p \in A$ guztietarako);

(D3) $p \leq q$ bada eta $q \in A$, orduan $p \in A$;

(D4) $p \in A$ bada, orduan $q \in A$ existitzen da, non $p<q$ den.

Nolakoak izango dira horrelako azpimultzoak? Argi dago $q$ zenbaki arrazionala bada eta

$$
A_{q}=\{p \in \mathrm{Q} \mid p<q\}, \quad \cdots \quad \cdots
$$

orduan $A_{q}$ ebakia dela eta bere gorena $q$ bera dela hain zuzen ere. Baina badaude beste ebaki batzuk era honetakoak ez direnak, adibidez

$A_{\sqrt{2}}=\left\{p \in \mathbb{Q} \mid p<0\right.$ edo $\left.p^{2}<2\right\}, \cdots \longrightarrow$

Argi dago $A_{\sqrt{2}}$ azpimultzoak (D1), (D2) eta (D3) baldintzak betetzen dituela. Bestalde, $p \in A_{\sqrt{2}}$ eta $p<0$ bada, orduan $p<q=0 \in A_{\sqrt{2}}$ izango dugu eta $p \in A_{\sqrt{2}}$ eta $p \geq 0$ bada, orduan $p<q=\frac{2 p+2}{p+2} \in A_{\sqrt{2}}$ izango dugu. Beraz $A_{\sqrt{2}}$ ere ebakia da. Azken finean, $A_{\sqrt{2}} \sqrt{2}$ baino hertsiki txikiagoak diren zenbaki arrazionalen multzoa izango da. Are gehiago, ebaki guztiak era honetakoak izango dira:

$$
A_{x}=\{p \in \mathrm{Q} \mid p<x\}
$$

non $x$ zenbaki erreal bat den. Gainera, $x$ izango da $A$-ren gorena $\mathbb{R}$-ko azpimultzo bezala. Hortaz, gorena hartzeak ebakien eta $\mathbb{R}$-ren arteko bijekzioa definitzen du.

Beraz, Dedekinden zenbaki errealak honela definitzen dira [2]:

$$
\mathbb{R}_{\text {Dedekind }}=\{A \subseteq \mathbb{Q} \mid A \text { Dedekinden ebakia }\}
$$


Ordena erlazioa horrela defini dezakegu:

$$
A \leq B \text { baldin eta } A \subseteq B \text { bada. }
$$

Erraz ikusten da honek $\mathbb{Q}$-ren ordena modu naturalean hedatzen duela: $A_{q} \leq A_{p}$ baldin eta soilik baldin $q \leq p$. Bi ebakien arteko batura eta alderantzizko elementua ere era sinplean defini daitezke:

$$
A+B=\{p+q \mid p \in A \text { eta } q \in B\} \quad \text { eta } \quad-A=\{p-q \mid p<0 \text { eta } q \in \mathbb{Q} \backslash A\}
$$

Era berean, erraz froga dezakegu $A_{p}+A_{q}=A_{p+q}$ eta $-A_{p}=A_{-p}$ ditugula. Biderkaduraren kasuan, berriz, definizioa zertxobait korapilatsugoa da:

$$
A \cdot B=\{p \cdot q \mid p, q \geq 0, \quad p \in A \quad \text { eta } \quad q \in B\} \cup A_{0},
$$

baldin eta $A, B \geq A_{0}$ badira eta $A \leq A_{0}$ edo $B \leq A_{0}$ badira, orduan era honetara erabil dezakegu aurreko definizioa:

$$
A \cdot B= \begin{cases}-((-A) \cdot B), & A \leq A_{0} \leq B \text { bada } \\ -(A \cdot(-B)), & B \leq A_{0} \leq A \text { bada } \\ (-A) \cdot(-B), & A, B \leq A_{0} \text { bada }\end{cases}
$$
daiteke.

Berriro ere $\left(\mathrm{R}_{\text {Dedekind }}, A_{0}, A_{1},+, \cdot, \leq\right)$, gorputz ordenatu osoa dela froga

\subsection{Weierstrassen eraikuntza}

Karl Weierstrass (1815-1897) matematikari alemaniarra izan zen bere lana atakan ikusirik zenbaki errealen definizio zehatz eta zuzen bat aurkeztu zuen lehenengoa (bere ikasleek helarazi zuten definizioa, berak ez baitzuen argitaratu). Garai hartan funtzio analitikoen teoriaren garapenean buru-belarri ari zen eta honen eragina ikus dezakegu bere eraikuntzan. Alde batetik, teoriak berak iradokitzen du jarraitu beharreko bidea. Bestetik, funtzio analitikoak aztertzeko zenbaki errealen nozio zehatza behar zuenez, bere lanerako probetxuzkoa izan zitekeen ildoari heldu zion [6]. Ez ditugu sakon aztertuko ikuspegi honen xehetasun guztiak eta abantailak, baina komenigarria da definizioak iradokitzen duen ideia azaltzea.

Gogora dezagun funtzio erreal bat analitikoa dela baldin eta lokalki berretura serie baten berdina bada, hau da,

$$
f(x)=\sum_{n=0}^{\infty} a_{n}\left(x-x_{0}\right)^{n}=a_{0}+a_{1}\left(x-x_{0}\right)+a_{2}\left(x-x_{0}\right)^{2}+a_{3}\left(x-x_{0}\right)^{3}+\cdots
$$


Zenbaki errealak eraikitzen

modukoa bada $x_{0}$-ren ingurune batean. Definizio horretan dago hain zuzen behar dugun ideia: antzeko moduan joka dezakegu zenbaki errealekin, zenbaki arrazionalen serieekin parekatuz.

Eraikuntza honen oinarrizko kontzeptua alikuota da: $n \in \mathbb{N}$ izanik, $1 / n$ adierazpenari $n$-ren alikuota deritzo. Kontuan izan behar da, formalki behintzat, $1 / n$ adierazpena definitu berri dugun objektua dela, ez ohiko zatikia. Hala ere, hori da, noski, buruan darabilgun ideia.

Zenbaki errealak eraikitzeko alikuota hauetaz osaturiko multimultzoak hartuko ditugu kontuan. Multimultzoaren kontzeptua multzo kontzeptuaren orokorpena da non elementu bakoitza behin baino gehiagotan ager daitekeen. Multimultzo bateko elementu baten anizkoiztasunak elementua multimultzo horretan zenbatetan agertzen den adieraziko du. Multimultzo hutsa ere onartuko dugu. Kortxeteen bidez adieraziko ditugu multimultzo hauek. Adibidez, [1/5, 1/3, 1/3, 1/3, 1/9] alikuotaz osaturiko multimultzo bat egongo da. Multzoen kasuan bezala, elementuen ordena ez zaigu axola, zein elementu agertzen diren eta zenbatetan agertzen diren baizik. Gure lanerako, multimultzo kontagarrietara mugatuko gara. (Egia esan, hau ez da guztiz beharrezkoa, aurrerago ezarriko ditugun baldintzek kasu kontagarrira ekarriko baikaitu).

Multimultzo hauek eraldatzeko bi modu onartuko ditugu:

(1) $1 / n$ alikuota multimultzo batean $n$ aldiz agertzen bazaigu, 1 idatz dezakegu horren ordez, hau da:

$$
\underbrace{1 / n+1 / n+\cdots+1 / n}_{n \text { aldiz }} \equiv 1 \text {. }
$$

(Bereziki $1 / 1 \equiv 1)$. Era berean, $1 /(k \cdot n)$ agertzen bada $k$ aldiz, $1 / n$ idatz dezakegu.

(2) Aurrekoa alderantziz ere egin dezakegu. Hau da, 1-en ordez $1 / n$ idatz dezakegu $n$ aldiz.

Multimultzo bati horrelako eraldaketa bat egin ondoren, lortutako multimultzoa hasierakoaren aldaera dela esango dugu. Notazio erraztearren, $k<n$ bada eta $1 / n$ alikuota $k$ aldiz agertzen bada, $k / n$ idatziko dugu:

$$
\underbrace{1 / n+1 / n+\cdots+1 / n}_{k \text { aldiz }} \equiv k / n \text {. }
$$

Era berean, $1 / 1$ agertzen bada $k$ aldiz $k / 1 \equiv k$ idatz dezakegu.

Aldaera hauek erabilita honelako erlazio bitarra defini dezakegu: Izan bitez $a$ eta $b$ bi multimultzo. Orduan $a \leq b$ dela esango dugu, baldin eta $a$-ren 
aldaera bakoitzaren azpimultimultzo finitu guztiak eralda baditzakegu, aurreko arauak erabiliz, $b$-ren aldaera baten azpimultimultzo bat lortzeko.

Begi bistakoa denez, erlazio hau erreflexiboa da eta erraz froga daiteke iragankorra ere badela. Bi propietate horiek betetzen dituen erlazio batek baliokidetasun erlazio bat definitzen du:

$$
a \sim b \text { baldin eta } a \leq b \text { eta } b \leq a .
$$

Beraz, pentsa genezake multimultzo kontagarrien baliokidetasun-klaseen familia eraikitzea izan litekeela zenbaki erreal positiboak definitzeko modua, baina pixka bat zorrotzago jokatu beharko dugu.

Eraikuntza hau zenbaki arrazional positiboen serieen ideian oinarrituta dago. Noski, serie hauek ez dute zertan konbergenteak izan eta haiek dira, hain zuzen ere, ekidin beharko ditugun «serieak». Horretarako definizio hau erabiliko dugu: $a$ multimultzoa finitua dela diogu, baldin eta beste elementu kopuru finituko $b$ multimultzo baterako, $a \leq b$ bada.

Definizio hau, noski, aurretik definitutako baliokidetasun erlazioarekin bateragarria da. Hau da, $a$ finitua bada bere baliokidetasun-klaseko edozein $a^{\prime}$ ere finitua izango da. Hortaz, $\mathcal{M}^{+}$multimultzo kontagarri finituen multzoa izanik, honela definitu zituen Weierstrassek zenbaki erreal positiboak:

$$
\mathbb{R}_{\text {Weierstrass }}^{+}:=\mathcal{M}^{+} / \sim
$$

Bi multimultzoren arteko batura erraz defini dezakegu:

$$
a+b=a \cup b .
$$

Multimultzoen arteko bildura multzoen arteko bilduraren antzekoa da, baina elementuen anizkoiztasuna kontuan hartu behar da, noski. Beraz, baturaren elementu baten anizkoiztasuna elementuak batugaietan dituen anizkoiztasunen batura izango da. Adibidez,

$$
[1 / 2,1 / 5]+[1 / 3,2 / 5]=[1 / 2,1 / 5,1 / 3,2 / 5] \equiv[1 / 2,1 / 3,3 / 5] .
$$

Biderketa ere modu naturalean definituko dugu. Horretarako alikuoten biderketa zatikien biderketa bezala definituko dugu. Hortaz, biderketa horrek batuketari buruz propietate banakorra izango balu bezala jokatuz, $a \cdot b$ multimultzoaren elementuak $\left(k_{i} \cdot k_{j}\right) /\left(n_{i} \cdot n_{j}\right)$ moduko elementuak dira, non $k_{i} / n_{i} \in a$ eta $k_{j} / n_{j} \in b$ diren. Adibidez,

$$
[1 / 2,1 / 5] \cdot[1 / 3,2 / 5]=[1 / 6,2 / 10,1 / 15,2 / 25] \equiv[1 / 6,1 / 5,1 / 15,2 / 25] .
$$


Bi eragiketa hauek definitu dugun baliokidetasun erlazioarekin bateragarriak dira, hau da,

$a \sim a^{\prime}$ eta $b \sim b^{\prime}$ badira, orduan $a+b \sim a^{\prime}+b^{\prime}$ eta $a \cdot b \sim a^{\prime} \cdot b^{\prime}$.

Hau izango da Weierstrassen zenbaki errealen eragiketa aljebraikoak eta ordena definitzeko modua: $\boldsymbol{a}=[a]$ eta $\boldsymbol{b}=[b]$ multimultzo kontagarri finituen baliokidetasun-klaseak badira, eta orduan

$$
\boldsymbol{a}+\boldsymbol{b}=[a+b], \quad \boldsymbol{a} \cdot \boldsymbol{b}=[a \cdot b] \quad \text { eta } \quad \boldsymbol{a} \leq \boldsymbol{b} \Leftrightarrow a \leq b
$$

izango dira. Bereziki, 0 multimultzo hutsaren baliokidetasun-klasea bada, orduan $\boldsymbol{a}+\mathbf{0}=\boldsymbol{a}, \boldsymbol{a} \cdot \mathbf{0}=\mathbf{0}$ eta $\mathbf{0} \leq \boldsymbol{a}$ izango da $\boldsymbol{a} \in \mathbb{R}_{\mathrm{Weierstrass}}^{+}$guztietarako.

Argi dagoenez, $q=k / n$ zenbaki arrazional positiboa bada eta $[k / n]$ multimultzoaren baliokidetasun-klasea $\boldsymbol{q}$ idazten badugu, orduan $q$ eta $\boldsymbol{q}$ identifika ditzakegu. Froga daiteke $\mathbb{R}_{\text {Weierstrass }}^{+}$-en eragiketa aljebraikoek $\mathbb{Q}^{+}$-enak modu naturalean hedatzen dituztela. Bereziki, $\boldsymbol{a} \cdot \mathbf{1}=\boldsymbol{a}$ izango da $\boldsymbol{a} \in \mathbb{R}_{\mathrm{Weierstrass}}^{+}$ guztietarako.

Eraikuntza honi bukaera emateko, badugu emaitza ba, gure multimultzoetan zenbaki errealen ohiko garapen hamartarra antzemateko aukera ematen diguna:

$a \in \mathcal{M}^{+}$multimultzo kontagarri finitu eta ez-huts bakoitza honako beste multimultzo baten baliokidea da:

$$
\left[a_{0}, a_{1} / 10, a_{2} / 10^{2}, a_{3} / 10^{3}, \cdots\right],
$$

non $n \in \mathbb{N}$ bakoitzerako $a_{n} \in\{0,1,2,3,4,5,6,7,8,9\}$ eta $a_{0} \in \mathbb{N}$.

Azkenik, zenbaki erreal positiboak ditugularik, zenbaki negatiboak modu erraz defini ditzakegu. $\mathbf{0}$ ez den $\mathbb{R}_{\text {Weierstrass }}^{+}$-eko $\boldsymbol{a}$ zenbaki erreal positibo bakoitzeko $\boldsymbol{- a}$ definituko genuke eta horrela Weierstrassen zenbaki errealen multzoa $\mathbb{R}_{\text {Weierstrass }}$ lortuko genuke. Ordena erlazioa eta eragiketa aljebraikoak ere modu naturalean hedatuz

$$
\left(\mathbb{R}_{\text {Weierstrass }}, \mathbf{0}, \mathbf{1},+, \cdot, \leq\right)
$$

gorputz ordenatu osoa dela egiazta dezakegu.

\section{IKUSPEGI ALJEBRAIKO BAT}

Cantorren eta Dedekinden eraikuntzak bi pausotan laburbil genitzake: lehenik zuzen arrazionala eraiki dugu (bigarren atalean egin dugun mo- 
duan, adibidez) eta honen ondoren zenbaki irrazionalak gehitu ditugu. Era berean, beste era batera baina zenbaki arrazionalak erabiltzen ditugu zenbaki arrazionalak Weistrassen lanean. Gainera, hiru eraikuntza hauetan nolabaiteko kutsu geometrikoa sumatzen dugu. Jakina, ez dago eragozpenik ez zenbaki arrazionalak erabiltzean, ezta intuizio geometrikoan ere; hala ere, matematikariok toki berera iristeko bide guztiak aztertzeko grina izan ohi dugu, hori da eta, neurri batean matematikarion zeregina. Guretzat ez da nahiko problema baten ebazpena, eta problema hori ahal dugun bezain argi eta sakon ulertzen saiatzen gara; eginbehar horrek bide guztiak ikertzeko beharra dakar.

Jarraian ikuspegi guztiz aljebraiko batetik ekingo diogu zenbaki errealen eraikitzeari. Gainera, zenbaki arrazionalak definitzeko zeregina saihestuko dugu, zenbaki osoak baino ez baititugu behar izango. Lan honetan, zenbaki erreala zifra dezimalen zerrenda infinitutzat hartzea litzateke oinarrizko intuizioa. Baina bide honetan laster topatuko ditugu gainditu beharreko oztopoak. Lana erraztearren, zifra bitarrekin lan egingo dugu. Azter dezagun zer den zenbaki erreal baten adierazpen bitar hori.

$$
\boldsymbol{a}=\left[\cdots\left(a_{-3}\right)\left(a_{-2}\right)\left(a_{-1}\right) a_{0}, a_{1} a_{2} a_{3} \cdots\right]
$$

moduko zerrenda infinitu bat izango da non:

- infinitu 0 -z hasten da, hau da, $n_{0} \in \mathbb{Z}$ existizen da non $a_{n}=0$ den $n<n_{0}$ guztietarako;

$-a_{n}$ guztiak 0 edo 1 dira, 0 ez den lehenengo zifra izan ezik, -1 ere izan baitaiteke. Zerrenda hori zenbaki positibo baten ordezkaria izango da $a_{n_{0}}=1$ denean eta negatibo batena $a_{n_{0}}=-1$ denean:

$$
\sum_{n \geq n_{0}} a_{n} \cdot 2^{-n} \quad \text { eta } \quad-\sum_{n \geq n_{0}}\left|a_{n}\right| \cdot 2^{-n} .
$$

Adibidez, $[11,100100 \cdots]$ eta $[(-1) 1,100100 \cdots]$ zerrenda infinituak, 57/16 eta $-57 / 16$ zenbaki errealen ordezkariak dira, hurrenez hurren $\left(\left(1 \cdot 2^{1}\right)+\left(1 \cdot 2^{0}\right)+\left(1 \cdot 2^{-1}\right)+\left(1 \cdot 2^{-4}\right)=57 / 16\right.$ delako $)$.

Kontuz ibili behar gara adierazpen hauekin. Izan ere,

$$
\frac{1}{2}+\frac{1}{2^{2}}+\frac{1}{2^{3}}+\frac{1}{2^{4}}+\cdots=1
$$

dugu eta beraz, $[0,1111 \cdots]$ eta $[1,0000 \cdots]$ adierazpen bitar desberdinak zenbaki beraren ordezkariak dira. Baina hau ez da arazo larria, eta erraz konpon dezakegu: 
Zenbaki errealak eraikitzen

$$
\left[a_{n_{0}} \cdots a_{n-1} a_{n} 011111111 \cdots\right] \quad \text { eta }\left[a_{n_{0}} \cdots a_{n-1} a_{n} 100000000 \cdots\right]
$$

berdintzat hartzearekin nahikoa dugu. Zorrotz jokatu nahiko bagenu, baliokidetasun erlazioa zehaztasunez definitu eta baliokidetasun-klaseekin lan egin genezake, baina, ikusiko dugunez, hau ez da gure buruhauste nagusia izango.

Egia esan, zuzenketa txiki hori eginez, eraikuntza honek zuzen defini ditzake zenbaki errealak. Beraz, non dago ba aurretik iragarritako arazo handia? Ba zenbaki errealen ohiko eragiketak egitean bururako gorde beharrekoetan. Errealen gorputz-egituraren deskribapenean, hortxe dago traba, hain justu. Ikus dezagun adibide erraz bat biderketaren kasuan:

$$
\begin{aligned}
{[1,1000 \cdots] \cdot[1,1000 \cdots] } & =[(1 \cdot 1),((1 \cdot 1)+(1 \cdot 1))((1 \cdot 0)+(1 \cdot 1)+(0 \cdot 1)) 000 \cdots] \\
& =[(1),(2)(1) 000 \cdots] \\
& =[(1+1), 01000 \cdots] \quad(1 . \text { kokapenean bururako gordez }) \\
& =[2,01000 \cdots] \\
& =[10,01000 \cdots] \quad(2 . \text { kokapenean bururako gordez }) .
\end{aligned}
$$

Orokorrean, 0 ez diren elementuen kopuru finitua duten bi zerrenden arteko biderkadura, zerrenda horiek adierazten dituzten batura finituen biderketa egitea besterik ez da. Biderketa erraz bat egiteko bururako bitan gorde behar izan dugu. Orokorrean prozesu hau konplexuagoa izan daiteke, zerrendek 0 ez diren infinitu elementu izan baititzakete:

$$
\begin{gathered}
{\left[a_{0}, a_{1} a_{2} \cdots\right] \cdot\left[b_{0}, b_{1} b_{2} \cdots\right]=} \\
{\left[\left(a_{0} \cdot b_{0}\right),\left(\left(a_{0} \cdot b_{1}\right)+\left(a_{1} \cdot b_{0}\right)\right)\left(\left(a_{0} \cdot b_{2}\right)+\left(a_{1} \cdot b_{1}\right)+\left(a_{2} \cdot b_{0}\right)\right) \cdots\right] .}
\end{gathered}
$$

Propietate banakorra erabiliz lortuko genuke aurreko adierazpena, baina, lehengo adibidean bezala, bururako gorde behar ditugu hainbat batura nahi dugun adierazpen bitarra lortzeko. Zerrendak infinituak direnez, baliteke infinitu aldiz bururako gorde beharra. Hortxe arazoa! Adibidez,

$$
[1,000 \cdots]=[0,(2) 000 \cdots]=[0,0(4) 000 \cdots]=[0,00(8) 000 \cdots]=\cdots=[0,000 \cdots] .
$$

Ez badiogu inongo mugarik jartzen bururako gordetzeari edozein zerrenda 0 -z soilik osaturiko zerrenda bihur dezakegu!

Arazo honi erantzuna eman zioten Frederick Faltin, Nicholas Metropolis, Bertrand Ross eta Gian-Carlo Rota matematikariek (begiratu bedi [3]). Azter ditzagun infinitu zeroz hasten diren zenbaki osoz osaturiko zerrendak. Hau da, $a_{n}$ bada, $\boldsymbol{a}$ zerrenda baten $n$-garren kokapenean dagoen zenbakia, orduan $n_{0} \in \mathbb{Z}$ existituko da, non $a_{n}=0$ den $n<n_{0}$ guztietarako:

$$
\left[a_{n_{0}} a_{n_{0}+1} a_{n_{0}+2} \cdots\right] .
$$


Gure eraikitze lana bideratzeko, zerrenda horiek zifra bitarren antzera uler ditzakegu,

$$
\sum_{n \geq n_{0}} a_{n} \cdot 2^{-n},
$$

baina kasu honetan an edozein zenbaki oso izan daiteke. Adibidez, $[5,(-3) 4000 \cdots$ ‥ zerrendak zenbaki hau adieraziko luke

$$
\left(5 \cdot 2^{0}\right)+\left((-3) \cdot 2^{-1}\right)+\left(4 \cdot 2^{-2}\right)=\text { «lau eta erdi». }
$$

Lehenbizi, Weierstrassen erainkuntzan bezala, zerrenda «finituetara» mugatu beharko gara (kasu honetan bornatu hitza erabiliko dugu, finitu ordez): Izan bedi $\boldsymbol{a}$ zenbaki osoen zerrenda. Zerrenda hori bornatua dela esango dugu, baldin eta $n_{1} \in \mathrm{Z}$ existitzen bada non

$$
\sum_{i=n_{0}}^{n}\left|a_{i}\right| 2^{n-i} \leq 2^{n} n_{1}
$$

den $n \geq n_{0}$ guztietarako.

Definizio honek dio, azken finean, $\Sigma_{n \geq n_{0}} a_{n} 2^{-n}$ seriea absolutuki kongerbentea dela $\left(\Sigma_{n \geq n_{0}}\left|a_{n}\right| 2^{-n}\right.$ konbergentea dela), besterik ez.

Definizioko desberdintzaren bi aldeetan $2^{n}$-rekin biderkatuz ikus dezakegu baliokidetasun hori. Gure eraikuntza zenbaki osoak soilik erabiliz egitea erabaki dugu eta definizio honek zatikiak saihesten laguntzen digu.

Eraikuntza honen mamia bururako gordetzearen prozesua zorrotz eta egokiro zehaztean datza, prozesu horrek esango baitigu zein zerrenda diren zenbaki erreal beraren ordezkari. Izan bedi

$$
z=[1,(-2) 000 \cdots]
$$

zenbaki osoen zerrenda. Zein zenbakiri dagokio?

$$
\left(1 \cdot 2^{0}\right)+\left((-2) \cdot 2^{-1}\right)=\text { «zero» }
$$

Hortaz, eraikuntza honetan $\boldsymbol{a}$ edozein zerrenda izanik, $\boldsymbol{a}$ eta $\boldsymbol{z}$-ren arteko baturak zenbaki beraren adierazle izan behar du, hau da:

$$
\begin{aligned}
{\left[\cdots a_{-3} a_{-2} a_{-1} a_{0}, a_{1} a_{2} a_{3} \cdots\right]+\mathbf{z} } & =\left[\cdots a_{-3} a_{-2} a_{-1}\left(a_{0}+1\right),\left(a_{1}-2\right) a_{2} a_{3} \cdots\right] \equiv \\
& \equiv\left[\cdots a_{-3} a_{-2} a_{-1} a_{0}, a_{1} a_{2} a_{3} \cdots\right]
\end{aligned}
$$

izan behar du. Izan ere, ikusi batuketa horretan gertatu dena: $a_{1}$-ri bi «erdi» kendu eta $a_{0}$-ri «unitate» bat gehitu diogu. Beraz, espero genuen bezala, $\boldsymbol{a}$ zenbaki bitartzat hartzen badugu, ez da aldatu. Hala ere, esan dezakegu 
batuketa hau $\boldsymbol{a}$-ren lehenengo kokapenean bururako gordetzearen baliokidea izan dela. Gainera hori edozein kokapenetara orokor dezakegu. $n \in \mathbb{Z}$ izanik, azter dezagun zerrenda hau

$$
\boldsymbol{n}=[\cdots 000 \underbrace{1}_{n . \text { kokapena }} 000 \cdots]
$$

Erraz ikus dezakegu $\boldsymbol{z} \cdot \boldsymbol{n}$ hau dela:

$$
\boldsymbol{n}=[\cdots 000 \underbrace{1}_{n \text {. kokapena }}(-2) 000 \cdots]
$$

Era berean, $(\boldsymbol{z} \cdot \boldsymbol{n})+\boldsymbol{a}$ izango da $\boldsymbol{a}$-ren $(n+1)$. kokapenean unitate bat bururako gordetzearen baliokidea. Hortaz, esan genezake $\boldsymbol{z} \cdot \boldsymbol{n}$ moduko zerrendak batuz kokapen bakoitzean nahi adina gorde ditzakegula bururako. Ideia hau da, hain justu, definizio hauen zergatia:

Zenbaki osoen zerrenda $\boldsymbol{b}$ bururakoen zerrenda dela esango dugu baldin eta

(1) $\boldsymbol{z} \cdot \boldsymbol{b}$ bornatua bada eta

(2) $\lim _{n \rightarrow \infty} \frac{b_{n}}{2^{n}}=0$ bada.

Gainera, izan bitez $\boldsymbol{a}$ eta $\boldsymbol{c}$ zenbaki osoen zerrendak. $\boldsymbol{a}$ eta $\boldsymbol{c}$ baliokideak direla esango dugu ( $\boldsymbol{a} \sim \boldsymbol{c}$ idatziko dugu), baldin eta $\boldsymbol{b}$ bururakoen zerrenda existitzen bada non

$$
a=c+(z \cdot b)
$$

den. Bururakoen zerrenden definizioko baldintzek bururako gordetzearen prozesua modu egokiro mugatzen dute. Eraikuntza honetara ekarri gaituen adibidean bertan ikus dezakegu hori. Demagun

$$
[1,000 \cdots]=[\cdots 000,000 \cdots]+(z \cdot b)
$$

dugula. Erraz ikus daiteke $\boldsymbol{b}$ elementuak honelako zerrenda hau izan behar duela:

$$
[1,248(16)(32) \cdots]
$$

Hau da, $b_{n}=2^{n}$, non $n \in \mathbb{N}$. Baina noski $\boldsymbol{b}$ ez da bururakoen zerrenda bat. Izan ere

$$
\lim _{n \rightarrow+\infty} \frac{b_{n}}{2^{n}}=\lim _{n \rightarrow+\infty} \frac{2^{n}}{2^{n}}=1 \neq 0 .
$$


Hortaz

$$
[1,000 \cdots] \nsim[\cdots 000,000 \cdots] .
$$

Emaitza honek agerian utzi digu gure zerrendak ohiko zenbaki bitarren moduan uler ditzakegula, eta horrek nolabait ziurtatzen digu bururako gordetzearen prozesua behar bezala definitu dugula.

$\boldsymbol{a}$ zenbaki osoen zerrenda bornatu bakoitzeko $\boldsymbol{a}$-ren baliokidea den beste $c$ zerrenda bat existitzen da baldintza hauek betetzen dituena:

(1) 0 ez den $\boldsymbol{c}$-ren lehenengo zenbakia 1 edo -1 da,

(2) lehenengo zenbaki hori -1 bada, hurrengoa 0 da,

(3) $c$-ren beste zenbaki guztiak 0 edo 1 dira,

(4) ez da existitzen $n_{1} \in \mathbb{Z}$, non $c_{n}=1$ den $n_{1}<n$ guztietarako, hau da, $c$ ezin da era honetakoa izan:

$$
\left[c_{n_{0}} \cdots c_{n_{1}-1} c_{n_{1}} 111111 \cdots\right] .
$$

Aurreko (1) eta (3) baldintzek ohiko adierazpen bitarra deskribatzen dute eta (4) baldintza aurretik aztertu dugu; beraz, ez dugu azalpen gehiagorik emango, baina (2) baldintza berriz argitu behar dugu. Baldintza hori gehitzearen arrazoia hauxe litzateke:

$$
\left[(-1), 1 a_{2} a_{3} a_{4} \ldots\right] \sim\left[0,(-1) a_{2} a_{3} a_{4} \cdots\right] .
$$

Zorrotz jokatzearren, onartu behar dugu adierazpen horiek ez datozela guztiz bat ohiko zenbaki bitar negatiboekin, baina eragozpen txiki honek ez du inolako eraginik eraikuntzaren garapenean.

Adibidez,

$-1,1=-\left(\left(1 \cdot 2^{0}\right)+\left(1 \cdot 2^{-1}\right)\right)=\ll$ minus bat eta erdi $\gg \neq(-1) \cdot 2^{-1}=,(-1)$

izan ohi da (minus zeinua gai guztiei dagokie), baina gure kasuan

$$
[(-1), 1]=\left((-1) \cdot 2^{0}\right)+\left(1 \cdot 2^{-1}\right)=\left\langle\text { minus erdia» }=(-1) \cdot 2^{-1}=[0,(-1)]\right.
$$

litzateke (zeinua gai bakoitzari baitagokio).

Hortaz, $\mathcal{M}$ zenbaki osoz osaturiko zerrenda bornatuen multzoa izanik, honela definitu zituzten Faltin, Metropolis, Ross eta Rota matematikariek zenbaki errealak:

$$
\mathbb{R}_{\mathrm{FMRR}}:=\mathcal{M} / \sim
$$


Bukatzeko, hauek dira orain arte inplizituki erabili ditugun eragiketa aljebraikoak

$$
\boldsymbol{a}+\boldsymbol{b}=\boldsymbol{c} \quad \text { eta } \boldsymbol{a} \cdot \boldsymbol{b}=\boldsymbol{d} \text { non } c_{n}=a_{n}+b_{n} \quad \text { eta } d_{n}=a_{n} \cdot b_{n} \text { diren. }
$$

Faltin, Metropolis, Ross eta Rota egileek ondo definituta daudela frogatu zuten, baita aztertu dugun baliokidetasun erlazioarekin bat datozela ere.

\section{ESKER ONAK}

Eskerrak eman nahi dizkiogu Euskal Herriko Unibertsitateari GIU12/39 erreferentziadun Ikerketa Taldearen laguntzagatik. Era berean, eskertu beharrekoak ditugu Eusko Jaurlaritzako Hezkuntza, Hizkuntza Politika eta Kultur Saileko doktoratu aurreko programa (BFI-2012-262) eta Ekonomia eta Lehiakortasun Espainiako Ministerioko MTM2012-37894-C02-02 proiektua.

Bestalde, Jorge Picado irakasleari artikulu hau idazteko bihotz eman izana eta eskainitako laguntza eta gomendioak eskertu nahi dizkiogu.

\section{BIBLIOGRAFIA}

[1] CANTOR G. 1872. «Über die Ausdenhung eines Satzes aus der Theorie der trigonometrischen Reihen». Mathematische Annalen, 5, 123-132.

[2] DEDEKIND R. 1963. «Essays on the Theory of Numbers: I. Continuity and Irrational Numbers. II. The Nature and Meaning of Numbers». (W. Woodruff Beman-en itzulpen baimendua). Dover Publications Inc., New York, 1963.

[3] FALTIN F., METROPOLIS N., ROSS B. eta ROTA G.C. 1975. «The Real Numbers as a Wreath Product». Advances in Mathematics, 16, 278-304.

[4] MCCULLOUGH D. 2006. "Gian-Carlo Rota (1932-1999)». (Hitzaldia) Oklahoma-Arkansas Section 68th Annual Meeting. http://www2.math.ou. edu/ dmccullough/ teaching/slides/rotamath.pdf.

[5] MÉRAY C. 1869. «Remarque sur la nature des quantités définies par la condition de servir de limites à des variables données». Revue de Sociétés Savantes, Sci. math. phys. nat., 2 (4), 280-289.

[6] TWEDDLE J.C. 2011. «Weierstrass's construction of the irrational numbers». Math Semesterber, 58, 47-58. 